Final 2015-16 Influenza Vaccination Coverage Estimates for Selected Local Areas, States, and the United States Available Online

Final 2015-16 influenza season vaccination coverage estimates are available online at FluVaxView (http://www. cdc.gov/flu/fluvaxview/). The online information includes estimates of the cumulative percentage of persons vaccinated through the end of each month during July 2015-May 2016, for selected local areas, states, and regions as designated by the U.S. Department of Health and Human Services, and the United States overall.

Analyses were conducted using National Immunization Survey-Flu influenza vaccination data for children aged 6 months-17 years and Behavioral Risk Factor Surveillance System (BRFSS) influenza vaccination data for adults aged $\geq 18$ years. Estimates are provided by age group and race/ethnicity. These estimates are presented in an interactive report (http://www.cdc.gov/flu/fluvaxview/interactive.htm) and are complemented by an online summary report (http://www.cdc. gov/flu/fluvaxview/coverage-1516estimates.htm).

Final 2015-16 influenza vaccination coverage estimates among pregnant women in the United States also are available online (https://www.cdc.gov/flu/fluvaxview/pregnantcoverage_1516estimates.htm). The online information includes national estimates of the percentage of women vaccinated before and during pregnancy since July 2015, among women who were pregnant during October 2015January 2016. Analyses were conducted using data collected from an Internet panel survey of pregnant women during March 29-April 7, 2016.

\section{Vol. 65, No. 36}

In the report, "Investigation of Escherichia coli Harboring the mor-1 Resistance Gene - Connecticut, 2016," the Acknowledgments should have included the following: Alycia McNutt, David Santoro, Christina Nishimura, Diane Noel, Katherine A. Kelley Public Health Laboratory, Connecticut Department of Public Health. 